\title{
Gender disparities in advanced endoscopy fellowship
}

\section{(ㄷ)(우우}

\section{Authors}

Jessica X. Yu ${ }^{1}$, Tyler M. Berzin², Brintha Enestvedt ${ }^{1}$, Michelle A. Anderson ${ }^{3}$, Violeta B. Popov ${ }^{4,5}$, Christopher C. Thompson $^{6}$, Allison R. Schulman ${ }^{3,7}$

Institutions

1 Division of Gastroenterology and Hepatology, Oregon Health and Science University, Portland, OR

2 Center for Advanced Endoscopy, Beth Israel Deaconess Medical Center and Harvard Medical School, Boston, Massachusetts, United States

3 Division of Gastroenterology and Hepatology, University of Michigan, Ann Arbor, Michigan, United States

4 Division of Gastroenterology, NYU Langone Medical Center, New York, New York, United States

5 Division of Gastroenterology, VA NY Harbor Healthcare System, New York, New York, United States

6 Division of Gastroenterology, Brigham and Women's Hospital, Boston, Massachusetts, United States

7 Department of Surgery, University of Michigan, Ann Arbor, MI

submitted 4.7.2020

accepted after revision 7.10 .2020

\section{Bibliography}

Endoscopy International Open 2021; 09: E338-E342

DOI 10.1055/a-1311-0899

ISSN 2364-3722

(C) 2021. The Author(s).

This is an open access article published by Thieme under the terms of the Creative Commons Attribution-NonDerivative-NonCommercial License, permitting copying and reproduction so long as the original work is given appropriate credit. Contents may not be used for commecial purposes, or adapted, remixed, transformed or built upon. (https://creativecommons.org/licenses/by-nc-nd/4.0/)

Georg Thieme Verlag KG, Rüdigerstraße 14,

70469 Stuttgart, Germany

Corresponding author

Jessica X. Yu MD, MS, Division of Gastroenterology \& Hepatology, Oregon Health and Science University, 3181 S.W. Sam Jackson Park Rd., Mail code: L461, Portland, OR 97239, United States

Fax: +1-503 494-8776

yujess@ohsu.edu
Supplementary material is available under https://doi.org/10.1055/a-1311-0899

\section{ABSTRACT}

Background and study aims Women remain underrepresented in gastroenterology, especially advanced endoscopy. Women represent $30 \%$ of general gastroenterology fellows; yet in 2019 , only $12.8 \%$ of fellows who matched into advanced endoscopy fellowship (AEF) programs were women.

Methods We administered a web-based survey to the program directors (PDs) of AEF programs that participated in the 2018-2019 American Society for Gastrointestinal Endoscopy (ASGE) match. We assessed PD and program characteristics, in addition to perceived barriers and facilitators (scale 1-5, 5=most important) influencing women pursuing AEF training.

Results We received 38 (59.3\%) responses from 64 PDs. $15.8 \%$ (6/38) of AEF PDs and 13.2\% (5/38) of endoscopy chiefs were women. By program, women represented $14.8 \%$ (mean) $\pm 17.0 \%$ (SD) of AEF faculty and $12.0 \%$ (mean) $\pm 11.1 \%$ (SD) of AEF trainees over the past 10 years. $47.4 \%$ (18/38) programs reported no female advanced endoscopy faculty and $31.6 \%$ (12/38) of programs have never had a female fellow. Percentage of female fellows was strongly associated with percentage of female AEF faculty $(B=0.43, P<0.001)$. Inflexible hours and call (mean rank $3.3 \pm 1.1)$, exposure to fluoroscopy $(2.9 \pm 1.1)$, lack of women endoscopists at national conferences/courses (2.9 $\pm 1.1)$ and lack of female mentorship $(2.9 \pm 1.0)$ were cited as the most important barriers to recruitment.

Conclusion We utilized a survey of AEF PDs participating in the ASGE match to determine program characteristics and identify contributors to gender disparity. Women represent a minority of AEF PDs, endoscopy chiefs, advanced endoscopy faculty and AEF trainees. Our study highlights perceived barriers and facilitators to recruitment, and emphasizes the importance of having female representation in faculty, and leadership positions in endoscopy. 


\section{Introduction}

Women are underrepresented throughout gastroenterology, making up only $30 \%$ of all trainees in this field [1]. This gender disparity is even more extreme in advanced endoscopy, which encompasses procedures such as endoscopic retrograde cholangiopancreatography (ERCP), endoscopic ultrasound (EUS), and more recently, endoluminal surgeries and advanced tissue resection techniques. Formalized training in this field via an advanced endoscopy fellowship (AEF) can be achieved by an additional one or two year-long fellowship through the American Society for Gastrointestinal Endoscopy (ASGE) match program. For the 2018-2019 academic year, women only represented $12.8 \%$ of the incoming fellows who matched to AEF programs through the ASGE match program.

A 2006 study found that the percentage of women gastroenterology trainees interested in AEF diminished as general gastroenterology training progressed [2]. Issues such as worklife balance, radiation exposure, and lack of mentorship have been speculated as potential contributors [2]. However, little is known about the current representation of women in AEF programs or the potential factors which may be contributing to these disparities. We aimed to survey program directors of AEF programs to determine program characteristics, in addition to perceived barriers and facilitators for women to pursue AEF training.

\section{Methods}

\section{Survey and subjects}

We developed and administered an anonymous 21-question web-based survey (Appendix 1) that was distributed to program directors of advanced endoscopy fellowships that participated in the 2018-2019 ASGE match, as identified through the ASGE. We assessed program director and program characteristics such as call structure and leave policies. In addition, we assessed the gender composition of faculty, current fellows and fellowship graduates over the past 10 years. We asked program directors to rank barriers and facilitators (Scale 1-5, 1= least important, 5 = most important) that may influence women pursuing advanced endoscopy training. Participants received initial email invitation with follow-up invitation 1 week afterwards. Approval for this study was obtained from the Oregon Health and Science University Institutional Review Board on February 26, 2020.

\section{Statistical methods}

We report categorical variables as proportions and continuous variables as means with standard deviations. We assessed program characteristics associated with higher proportion of female advanced endoscopy fellowship program graduates. To test differences, student's $t$-test was used for continuous variables and chi-squared test was used for categorical variables. Linear regression was used to assess effect of continuous variables on proportion of female advanced endoscopy fellowship program graduates. All statistical analyses were performed using StataMP v14.1.412 (StataCorp LLC, College Station,
Texas, United States). $P<0.05$ was considered statistically significant.

\section{Results \\ Program characteristics: faculty}

A total of 64 AEF programs participated in the 2018-2019 ASGE match. Of the 64 program directors, 38 (59.3\%) completed the survey. Program director characteristics are summarized in $>$ Table 1 , and program characteristics are summarized in $>$ Table 2. Seven of the 64 program directors (11\%) were women. Six of seven female program directors (86\%) responded to the survey and represented $16 \%$ (6/38) of all AEF program directors who responded. Women represented $13.2 \%$ (5/38) of endoscopy chiefs, $39.5 \%$ of general gastroenterology fellowship directors (15/38), $21.1 \%$ of gastroenterology division chiefs $(8 / 38)$ and $21.1 \%$ of internal medicine department chairs $(8 / 38)$. Women represented $18.1 \%$ of the total number advanced endoscopy faculty amongst all programs (38/210). By program, the mean percentage $( \pm S D)$ of advanced endoscopy faculty who were women was $14.8 \%( \pm 17.0 \%)$. Eighteen of 38 programs $(47.4 \%)$ reported no women advanced endoscopy faculty.

\section{Program characteristics: Fellows}

Women represented $14.0 \%$ (6/43) of all current advanced endoscopy fellows. Over the past 10 years, women represented $13.6 \%$ (48/352) of total fellows amongst all responding AEF programs. By program, the mean percentage of females interviewed was $25.9 \%( \pm 18.6 \%)$ and the mean percentage of female advanced endoscopy fellows currently in training was $18.2 \%( \pm 39.2 \%)$ ( Table 2 ). Historically, over the past 10 years, the mean percentage of female graduates by program was $12.0 \%$ ( $\pm 11.1 \%)$. Twelve (31.6\%) programs have never had a female advanced endoscopy fellow.

The majority of programs required fellows to be on-call one night per week $(61.3 \%, n=19 / 31)$ and one weekend per month (76.9\%, n = 20/30). Twenty-two programs (77.1\%) had a parental leave policy.

\section{Factors impacting women training in advanced endoscopy}

Mean rank $( \pm S D)$ of factors cited by program directors which discourage women from pursuing fellowship in advanced endoscopy were: difficult or inflexible hours and call (3.3 \pm $1.1)$, exposure to fluoroscopy during childbearing age $(2.9 \pm$ 1.1), lack of women endoscopists at national conferences and courses (mean rank $2.9 \pm 1.1$ ) and lack of mentorship for female trainees $(2.9 \pm 1.0)$ as the most important barriers hindering recruitment of women to AEF programs. Mean rank ( \pm SD) of factors cited by program directors identified as potentially facilitating women to pursuing a career in advanced endoscopy were: education on fluoroscopy safety $(3.6 \pm 1.8)$, increasing the visibility of women advanced endoscopists at national meetings and endoscopy courses $(3.5 \pm 1.1)$ and increasing the number of female mentors $(3.5 \pm 1.1)$ ( $\triangleright$ Fig. 1$)$. 
- Table 1 Program director characteristics $(\mathrm{N}=38)$.

\begin{tabular}{|l|r|}
\hline Program director demographics $(\mathbf{N}=\mathbf{3 8})$ & Variables \\
\hline Female gender & $6(15.8 \%)$ \\
\hline Male gender & $32(84.2 \%)$ \\
\hline Years in practice & \\
\hline$<5$ & $3(7.9 \%)$ \\
\hline $5-9$ & $8(21.1 \%)$ \\
\hline$>10$ & $27(71.1 \%)$ \\
\hline
\end{tabular}

The percentage of women pursuing advanced endoscopy fellowship was strongly associated with percentage of female advanced endoscopy faculty $(B=0.43, P<0.001)$ in the program (> Fig.2). Percentage of women pursuing advanced endoscopy fellowship was higher in programs with female leadership, with the strongest association in programs with female endoscopy chiefs ( $19.6 \%$ vs $10.6 \%, P=0.09)$. There was no significant association between percentage of female advanced endoscopy fellows and call structure $(P=0.77)$ or parental leave policy $(P=0.85)$.

\section{Discussion}

Diversity is important in the medical workforce and has proven to increase creativity and innovation, benefiting research, education and patient care in academic centers [3]. Several studies have demonstrated that women physicians promote improved teamwork and patient-centered communication [4]. Furthermore, a diverse faculty provides more opportunities for mentoring the next generation of advanced endoscopists who, in turn, can better support and serve a diverse patient population.

The current study provides further clarity on the significant gender disparity that currently exists within AEF programs. We found that women only represent $14 \%$ of current AEF fellows, and only $14 \%$ of all AEF program graduates in the past 10 years. Furthermore, 12 programs had never had a female advanced endoscopy fellow. Women are underrepresented in other interventional subspecialty fields such interventional radiology and interventional cardiology. Women accounted for only $12 \%$ of first-year fellows in interventional cardiology 2018 [5] and 14 $\%$ of vascular and interventional fellows in 2017 [1]. Traditionally, surgery was another field where women are underrepresented. Encouragingly, recent studies have shown that with efforts such as establishing mentorship programs for early career women through the Association of Women Surgeons and the American College of surgeons, the rates of women in general surgery programs have increased from $14 \%$ in 2001 to $40 \%$ in 2017 [6,7]. Thus, similar efforts should be made to improve the representation of women in AEF programs.

Our study also highlights the importance of having women in leadership roles in endoscopy. We found that AEF programs with more female faculty and endoscopy chiefs were more likely to have female advanced endoscopy fellows. Moreover, program directors similarly ranked increasing the number of fe-
- Table 2 Program characteristics $(\mathrm{N}=38)$.

\begin{tabular}{|c|c|}
\hline Program Details & Variables \\
\hline Female internal medicine department chair & $8(21.1 \%)$ \\
\hline Female gastroenterology division chief & $8(21.1 \%)$ \\
\hline Female general gastroenterology program director & $15(39.5 \%)$ \\
\hline Female internal medicine department chair & $5(13.2 \%)$ \\
\hline $\begin{array}{l}\text { Percentage of female advanced endoscopy faculty } \\
\text { per program }\end{array}$ & $\begin{array}{l}\text { Mean } 14.8 \% \\
(\text { SD } 17.0 \%)\end{array}$ \\
\hline $\begin{array}{l}\text { Percentage of female fellows interviewed per pro- } \\
\text { gram }\end{array}$ & $\begin{array}{l}\text { Mean } 25.9 \% \\
(\text { SD } 18.6 \%)\end{array}$ \\
\hline $\begin{array}{l}\text { Percentage of female fellows current per program } \\
(n=33)^{1}\end{array}$ & $\begin{array}{l}\text { Mean } 18.2 \% \\
(\text { SD } 39.2 \%)\end{array}$ \\
\hline $\begin{array}{l}\text { Percentage of female fellow graduates over the } \\
\text { past } 10 \text { years per program }(n=34)^{1}\end{array}$ & $\begin{array}{l}\text { Mean } 12.0 \% \\
(\text { SD } 11.1 \%)\end{array}$ \\
\hline \multicolumn{2}{|l|}{ Night call schedule $(\mathrm{N}=31)^{1}$} \\
\hline $1 \times /$ week & $19(61.3 \%)$ \\
\hline $2 \times /$ week & $3(9.7 \%)$ \\
\hline $3 \times /$ week & $2(6.5 \%)$ \\
\hline$>3 \times /$ week & $7(22.6 \%)$ \\
\hline \multicolumn{2}{|l|}{ Weekend call $(\mathrm{N}=30)^{1}$} \\
\hline $1 \times /$ month & $20(76.9 \%)$ \\
\hline $2 \times /$ month & $5(16.7 \%)$ \\
\hline $3 \times /$ month & $5(16.7 \%)$ \\
\hline \multicolumn{2}{|l|}{ Parental leave policy } \\
\hline No & $2(6.5 \%)$ \\
\hline Yes & $27(77.1 \%)$ \\
\hline Unsure & $6(17.1 \%)$ \\
\hline
\end{tabular}

male mentors and increasing the visibility of women advanced endoscopists at national conferences as two of the top three facilitators to improving gender balance within this subspecialty However, women only represented $13.2 \%$ of endoscopy chiefs, $39.5 \%$ of general gastroenterology fellowship PDs, $21.1 \%$ of gastroenterology division chiefs, and $21.1 \%$ of internal medicine department chairs. Addressing this disparity is of utmost importance. Beyond the importance of equity, studies have demonstrated that women in leadership also bring additional benefits to organizations, more often focusing on collaborative long-term goals, with improved organizational and financial performance [8].

Work-life balance has commonly been cited as a barrier to gender balance [9]. AEF program directors in the current study cited the perception of inflexible work hours as the most important barrier to women participating in AEF. Interestingly, we did not find any significant association with call structure or parental leave structure and the percentage of female advanced endoscopy fellows at each program. However, we acknowledge 


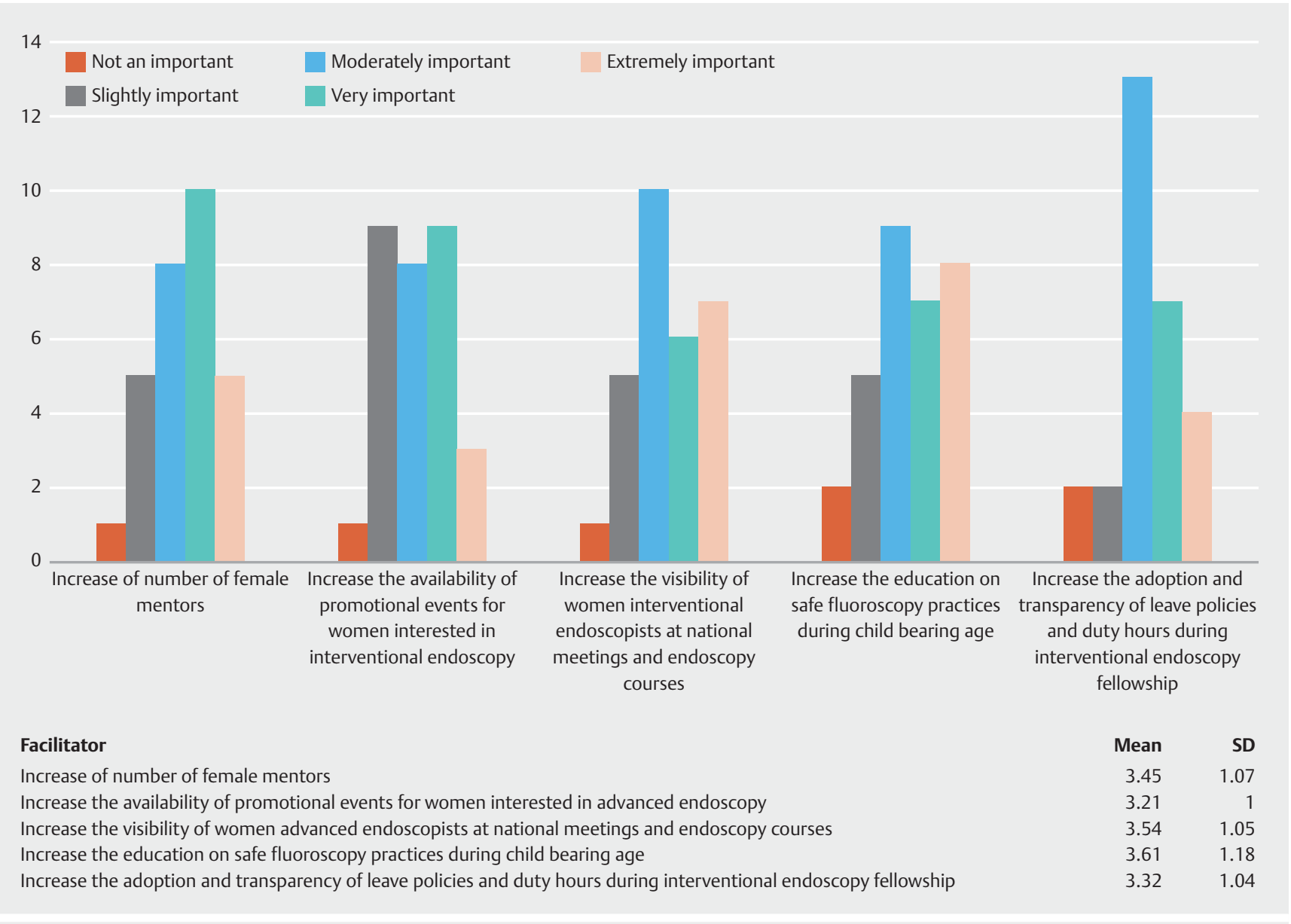

- Fig. 1 Potential facilitators to women pursuing a career in advanced endoscopy.

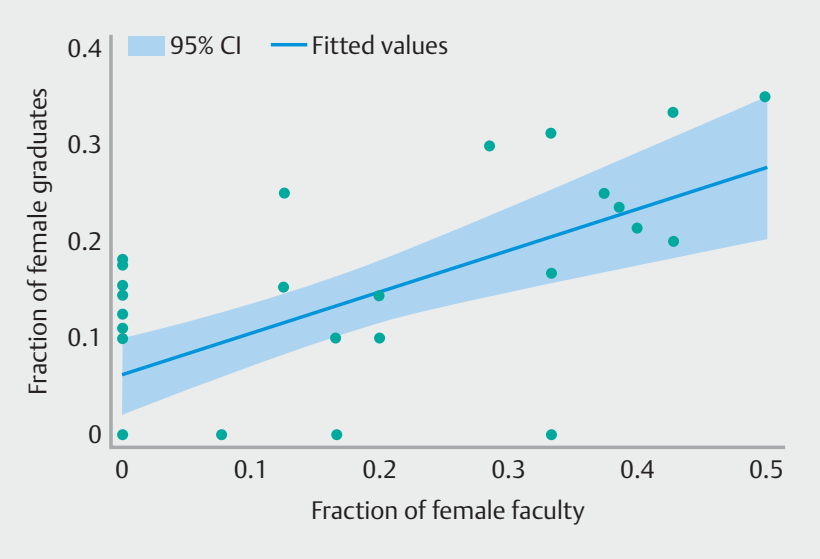

- Fig. 2 Fraction of female graduates over the past 10 years is positively associated with fraction of female advanced endoscopy faculty $(B=0.43, P<0.001)$.

that this study is small and therefore may be under-powered to detect this correlation.

Radiation exposure during childbearing age has also been raised as a concern for women pursuing AEF. Radiation exposure has been cited as a deterrent to women pursuing training in other fields including intervention cardiology and interventional radiology $[10,11]$. Interestingly, a 2016 study found that this was the most commonly cited deterrent for female medical students considering intervention radiology [12]. That same study found that male students also shared this concerned at equally as high rates [12]. In response to this, comprehensive educational materials on radiation safety have been made available by professional societies such as the Society of Interventional Radiology [13]. Gastroenterology societies should consider making similar such materials widely available for gastroenterology fellows as well.

There are several limitations of this study. First, the response rate was $60 \%$ which leads to the possibility that there may be sampling bias. However, recent literature has suggested that a response rate for survey studies approximating $60 \%$ should be the goal of researchers and is acceptable in regard to non-response bias [14]. In addition, we acknowledge that we only included programs that participated in the ASGE match, and thus, did not capture information from AEF programs that are not part of the match. Furthermore, our survey was cross-sectional. While we queried fellow gender composition over the past 10 years, we do not present trends in gender composition over time as recall bias may influence these results. Systematically collecting and reporting such information will be helpful in 
tracking future effects of improvement efforts. Our study results rely on a PD perspective and were not directly correlated with fellow responses, as those were not queried. Although these perceptions may be indirect, we believe they remain a surrogate for fellow perceptions. Finally, PD perceptions match with similar studies involving practicing gastroenterologists [15] and trainees in interventional radiology and interventional cardiology $[10,11]$. Importantly, as PDs are in positions of power to address these barriers, understanding their perspective remains important. Additional PD and fellow demographics such as age were not obtained in the current survey, but will be the subject of future studies. Additional studies from a trainees' perspective would complement this study well.

To strive towards equity in medical subspecialties and leadership, academic medicine requires both individual and organizational action. We should actively seek to increase the number of women being recruited to AEF programs and faculty positions, in addition to implementing transparent structural changes and policies to help the advancement of these women during their careers.

\section{Conclusion}

We found that women are underrepresented in AEF training programs as well as among AEF faculty, AEF program directors, and endoscopy directors. While there are serious concerns regarding inflexible hours and fluoroscopy exposure, efforts to increase the representation of women in endoscopy as faculty and as endoscopy leaders may help improve the gender disparity seen in AEF programs.

\section{Competing interests}

Dr. Berzin is a consultant for Boston Scientific, Medtronic, and Wision Al. Dr. Anderson is a consultant for Boston Scientific and Olympus. Dr. Thompson is a consultant and receives institutional research grants from Apollo Endosurgery, receives an institutional research grant from Aspire Bariatrics, is a general partner in the Healthcare Venture Fund for BlueFlame, is a consultant for Boston Scientific, a consultant for Covidien/Medtronic, a consultant and advisory board member for Fractyl, a consultant and receives an institutional grant from GI Dynamics, has ownership interest in GI Windows, is a consultant for and has received equipment loans from Olympus/Spiration, receives an institutional research grant from Spatz, and is a consultant and advisory member for and receives a research grant from USGI Medical. Dr. Schulman is a consultant for Apollo Endosurgery, a consultant for Boston Scientific, a consultant for MicroTech, and has received grant support from GI Dynamics.
[1] ACGME Residents and Fellows by Sex and Specialty. 2017: Available from: https://www.aamc.org/data-reports/workforce/interactivedata/acgme-residents-and-fellows-sex-and-specialty-2017

[2] Pollack MJ, Cummings LC, Wong RC et al. Gender disparities and gastroenterology trainee attitudes toward advanced endoscopic training. Gastrointest Endosc 2010; 72: 1111

[3] Nielsen MW, Alegria S, Borjeson L et al. Opinion: Gender diversity leads to better science. Proc Natl Acad Sci USA 2017; 114: 1740-1742

[4] Levinson W, Lurie N. When most doctors are women: what lies ahead? Ann Intern Med 2004; 141: 471-474

[5] Percentage of First-year Fellows by Gender and Type of Medical School Attended 2020. Available from: https://www.abim.org/about/ statistics-data/resident-fellow-workforce-data/first-year-fellows-bygender-type-of-medical-school-attended.aspx

[6] Hiba AA, Welsh DJ, Paramo JC et al. 2018 ACS Governors Survey: Gender inequality and harassment remain a challenge in surgery. 2018: Available from: https://bulletin.facs.org/2019/09/2018-acsgovernors-survey-gender-inequality-and-harassment-remain-a-challenge-in-surgery/

[7] Abelson JS, Chartrand G, Moo TA et al. The climb to break the glass ceiling in surgery: trends in women progressing from medical school to surgical training and academic leadership from 1994 to 2015. Am J Surg 2016; 212: 566-72 e1

[8] McDonagh KJ, Hoss MAK et al. The leadership gap: ensuring effective healthcare leadership requires inclusion of women at the top. Open J Leadership 2014; 3: 20-29

[9] Granato CM, Kaul V, Kothari T et al. Career prospects and professional landscape after advanced endoscopy fellowship training: a survey assessing graduates from 2009 to 2013. Gastrointest Endosc 2016; 84: 266-271

[10] Wah TM, Belli AM. The Interventional radiology (IR) gender gap: a prospective online survey by the Cardiovascular and Interventional Radiological Society of Europe (CIRSE). Cardiovasc Intervent Radiol 2018; 41: 1241-1253

[11] Yong CM, Abnousi F, Rzeszut AK et al. Sex differences in the pursuit of interventional cardiology as a subspecialty among cardiovascular fellows-in-training. JACC Cardiovasc Interv 2019; 12: 219-228

[12] Perez YV, Kesselman A, Abbey-Mensah G et al. A glance at genderspecific preferences influencing interventional radiology selection. J Vasc Interv Radiol 2016; 27: 142-3 e1

[13] Society of Interventional Radiology Safety Kit: Society of Interventional Radiology. Available from: https://www.sirweb.org/practiceresources/toolkits/quality-and-safety-toolkit/radiation-safety

[14] Fincham JE. Response rates and responsiveness for surveys, standards, and the Journal. Am J Pharm Educ 2008; 72: 43

[15] Rembacken B], Dixon S, Albuquerque A et al. Barriers and bias standing in the way of female trainees wanting to learn advanced endoscopy. United European Gastroenterol J 2019; 7: 1141-1145 